This is the final corrected pre-print text. The published version can be found at: Environmental Science and Policy http://dx.doi.org/10.1016/j.envsci.2012.10.006

\title{
Examining Equity: a multidimensional framework for assessing equity in payments for ecosystem services
}

\author{
Authors: Melanie McDermott ${ }^{a},{ }^{*}$ Sango Mahanty ${ }^{b}$ and Kate Schreckenberg ${ }^{c, d}$ \\ ${ }^{a}$ Department of Human Ecology, Rutgers University, USA. \\ ${ }^{b}$ College of Asia and the Pacific, The Australian National University, Australia. \\ ${ }^{\mathrm{c}}$ Faculty of Engineering and the Environment, University of Southampton, UK. \\ ${ }^{\mathrm{d} I n s t i t u t e}$ for Life Sciences, University of Southampton, UK.
}

\section{*Corresponding author at:}

Department of Human Ecology, Cook Office Building, 55 Dudley Road, New Brunswick, NJ 08901, USA. Telephone: +1-848-932-9153, Fax: +1-848-932-6667.

Email addresses: mmcdermott@aesop.rutgers.edu (M. McDermott), sango.mahanty@anu.edu.au (S. Mahanty), k.schreckenberg@soton.ac.uk (K. Schreckenberg).

\section{ABSTRACT}

Concern over social equity dominates current debates about payments for ecosystem services and reduced deforestation and forest degradation (REDD+). Yet, despite the apprehension that these initiatives may undermine equity, the term is generally left undefined. This paper presents a systematic framework for the analysis of equity that can be used to examine how local equity is affected as the global value of ecosystem services changes. Our framework identifies three dimensions that form the content (the what) of equity. The first, distributive equity, addresses the distribution of benefits and costs. The second, procedural equity, refers to decision-making. These are linked by the third dimension, contextual equity, which incorporates the pre-existing conditions that limit or facilitate people's access to decision-making procedures, resources and, thereby, benefits. The framework then asks how these dimensions are shaped by the scale and target group of concern (who), the framing of goals with respect to equity (why), and, crucially, how the decisions about the content, target and aims of equity are taken. By spurring debate around the fundamental ethical values at stake, this framework can guide analysts, policymakers and planners towards more open and inclusive processes for defining equity, along with affirmative efforts to engage marginalised people.

Keywords: Equity, PES, REDD+, ecosystem services, justice 


\section{Introduction}

In response to persistent and alarming rates of environmental degradation, a growing number of initiatives promulgate better valuation of resources in order to reverse or halt this trend (e.g. TEEB, 2010). A burgeoning literature on payments for ecosystem services (PES) ${ }^{1}$ describes how the creation of markets for these newly valued ecosystem services provides incentives for ecosystem managers to manage their resources more sustainably. However, optimism about the potential of PES is counteracted by mounting concerns that local equity may be undermined, or that existing inequalities may be worsened, as the local value ${ }^{2}$ of ecosystem services is transformed by changes in their global value - whether caused by market forces or regional and global initiatives to pay for them (Ghazoul et al., 2010; Sikor et al., 2010). Such value shifts may serve the interests of elites and intermediary organisations, while local actors lose access to significant livelihood resources without any significant benefits or influence over the terms of trade (Corbera and Brown, 2010; Kosoy and Corbera, 2010; McAfee and Shapiro, 2010; Pascual et al., 2010).

Just how quickly ecosystem service values can change is illustrated by the growth of the market in forest carbon credits from just 0.3mtCO2e in 2003 to 30mtCO2e in 2010 (Diaz et al., 2011). This sudden commercial valuation of trees and forests for the carbon dioxide they sequester imposes novel management constraints on local people at the same time as it attracts substantial new funds into the forest sector. Over forty developing countries (and many private companies) are moving to capitalise on this new commodity by developing and implementing national programmes to achieve 'Reduced Emissions from Deforestation and forest Degradation, conserving and enhancing forest carbon stocks, and sustainably managing forests' (REDD+). Initial estimates of potential income flows to developing countries were as high as $\$ 30$ billion per year (Peskett et al., 2008). The challenge of ensuring equity across multiple actors and scales has been a critical concern driving developments in the REDD+ debate at both international and national levels (Peskett et al., 2011a).

Discussions around global environmental governance reflect the centrality of equity to just and sustainable outcomes, yet lack clarity regarding the definition and components of equity. Without a clear definition of which aspects of equity are being pursued and how, it is difficult

\footnotetext{
${ }^{1}$ The early literature on PES (e.g. Wunder, 2005) uses the term to refer to payments for environmental services, focusing mostly on payments for water and for biodiversity conservation. In this paper we follow the prevalent practice of using PES to refer to payments for ecosystem services, where ecosystem services are defined by the Millennium Ecosystem Assessment as provisioning, cultural, supporting and regulating services (MA, 2005).

${ }^{2}$ We are construing value in its broadest sense, to embrace exchange value (price), use value, cultural value (meaning) and ethical principle.
} 
to evaluate the impact of policies and programmes on equity, and impossible to plan for it effectively. Moreover, an explicit discussion of the equity goals of a policy or programme, i.e. of what constitutes a positive impact on social equity in a particular context, would provide an opening for people to have a say in setting up the structures that will condition their future welfare (e.g. the design of REDD+). Although past research has made progress in mapping important dimensions of equity in terms of governance processes and benefit distribution (Corbera and Schroeder, 2011; Mahanty et al., 2006; McDermott and Schreckenberg, 2009), we still lack a comprehensive framework that identifies and brings together various dimensions of equity in an integrated, systematic and rigorous way. This paper aims to fill that void.

Frameworks "provid[e] a common set of potentially relevant variables and their subcomponents" (Ostrom 2009: 419) for use in planning, monitoring, evaluating and research. They help to define a commonly understood vocabulary for analysis and debate. By unpacking the critical elements of a complex topic they identify popular elisions and omissions. Our framework lays out the elements of equity in relation to each other in order to develop the clear conceptual basis that is necessary to operationalise and apply the term: for example, to develop and monitor indicators of equity in practice.

As it does not present an explanatory model of change, the proposed framework cannot by itself account for the causes of inequity. This paper does, however, aspire to lay the essential foundation for causal inquiry of the sort that could account for how local equity is affected by exogenously driven changes in the value of ecosystem services. Our emphasis on the local scale complements the important body of literature that examines equity and justice with respect to global climate regimes (e.g. Grasso, 2007; Heyward, 2007; Klinsky and Dowlatabadi, 2009). These works focus on nation-states as the locus of concern, with limited attention to sub-national groups, and still less to the local communities where climate change impacts are felt. Despite the absence of local input, some negotiations over REDD+ manifest concern with local equity, eliciting debate on appropriate 'safeguards' (McDermott et al., 2012). The proposed equity framework is directly relevant to these efforts.

The paper begins by considering how equity relates to justice and other closely allied concepts. We then draw from the literature on ethical and political philosophy to develop a framework for the analysis of equity. The framework has three core dimensions: distributive, procedural and contextual equity, which together describe the substantive content (the what) of equity. Three additional parameters are necessary for a complete analysis of equity in a given intervention: its goals in relation to equity (why), the target groups, or social scale, of equity (who) and 'how' the goals, targets and content of equity were decided upon in the first 
place (cf. Fraser, 2009). We illustrate these elements of equity by reference to a range of different marketed ecosystem services, from irrigation water to community forest products, natural gas and sequestered carbon. In addition, we draw lessons from how equity challenges are being confronted in processes for governing ecosystem service markets such as certification schemes, access-and-benefit sharing legislation and REDD+ programmes. The paper concludes with a discussion of how this framework contrasts with other prominent concepts and approaches: rights, efficiency and poverty alleviation.

\section{Justice and equity}

Justice, fairness and equity all imply "fair treatment or due reward" (Schroeder and Pisupati, 2010:13). Konow (2003:1189) points out that these terms reflect Adam Smith's notion of an "impartial spectator whose judgment is not biased by any personal stake." Fairness and the lack of self-interest are also emphasised in the Oxford English Dictionary (2010) definition of equity as "the quality of being equal or fair; fairness, impartiality; even-handed dealing".

While we draw on the long lineage of literature on justice to define equity, we find the term equity more suited to our aims, which involve evaluating change in the relative situation of particular groups in society. Common usage defines justice in terms of rights: "The quality of being (morally) just or righteous...conformity (of an action or thing) to moral right, or to reason, truth, or fact" (OED, 2010). By contrast, equity is comparative; it is principally concerned with relationships between people, and with their relative circumstances (Grasso, 2007).

In legal terms, equity refers to "a branch of law that developed alongside common law in order to remedy some of its defects in fairness and justice" (OED, 2010). In British and American courts legal principles concerned with equity supplement strict rules of law that do not consider any special hardships or other constraints faced by the defendant (Worthington, 2006). Equity thus contrasts with the common depiction of Justice as a blindfolded woman holding scales and a sword (Resnick and Curtis, 2010), who metes out equal treatment for all, regardless of personal advantage or disadvantage (such as extreme poverty). If Justice is blind, Equity has her eyes wide open.

A further contrast arises from another popular notion of justice: retribution, as evoked by the dictum "An eye for an eye" (cf. Schroeder and Pisupati, 2010). Under such an approach, a just judgement could be rendered that was inequitable in its impacts (e.g. penalising a starving person for stealing food). These two interpretations of justice extend beyond the notion of "justice as fairness" (Rawls, 1971, 2001) to incorporate an explicitly moral or legalistic dimension. 
Compensatory justice makes a gentler, but similarly rights-based demand for the compensation of parties that have been harmed by the actions of others (Klinsky and Dowlatabadi, 2009). Once the scope of justice is expanded to encompass the powerful notion of 'social justice', the blindfolded goddess must open her eyes and consider outcomes for society as a whole, i.e. what would make for a 'just society' (Tisdell, 2003).

Equity is closely associated with equality, and with it the commonly accepted notion that fairness demands "equal consideration for all" (Sen, 1992:17). Yet, equity and equality are distinguished in important ways. Though the dictionary pairs 'equal' with 'fair', we often find that a 'fair share', the measure of equity, is not necessarily an equal share. Furthermore, what is regarded as a 'fair share' varies according to different situations and cultures (Fisher, 1989). Opposed to a relativistic notion of equity, Sen (1992:ix) argues that all conceptions of equity are founded upon the equality of something - whether income, utility, welfare, opportunity, rights or liberties. He contends that ethical reasoning must be "credible from the viewpoint of others", underscoring a key reason for advancing equity as a fundamental criterion for evaluation. He further notes that equality in a chosen "focal variable" will often necessitate inequalities in others (e.g. equality of opportunity will result in unequal achievements in wealth).

\subsection{Distributive justice}

Fraser (2009) and Schlosberg (2007) argue that the last four decades of scholarship on justice have focused on one key dimension: distributive equity. Fundamentally, these theories of justice (categorised in Table 1) are concerned with the distribution of 'goods' and 'bads' in society and the principles by which these benefits and burdens are, or should be, distributed. Distributive justice focuses on the allocation among stakeholders of costs and benefits resulting from, for example, environmental policy or resource management decisions and hence represents primarily (but not exclusively) the economic dimension of equity (Mahanty et al., 2006).

Table 1. Principles of distributive justice

\begin{tabular}{|l|l|l|}
\hline Type & Theory & Principle \\
\hline \multirow{2}{*}{$\begin{array}{l}\text { Consequence- } \\
\text { based }\end{array}$} & Utilitarianism & Greatest good for greatest number \\
\cline { 2 - 3 } & Welfare economics & Individual utility contributes to aggregate welfare \\
\hline \multirow{4}{*}{ Rules-based } & Libertarianism & Equal rights \\
\cline { 2 - 3 } & Egalitarianism & Equal shares \\
\cline { 2 - 3 } & Merit-based & Rewards proportional to inputs \\
\cline { 2 - 3 } & Need-based & Rewards according to need \\
\hline
\end{tabular}


Theories of distributive justice fall into one of two categories: consequence-based or rulesbased. Modern welfare economics (a refinement of utilitarianism) understands the social good to mean the maximisation of individual utilities, aggregated according to a 'social welfare function' (Konow, 2003; Samuelson, 1947). The market, more or less fettered according to different economic schools, is the mechanism for achieving the efficient distribution of social costs and benefits, namely one that maximises social welfare. This has been the guiding logic for the efficacy of PES in conserving ecosystem services for the least cost (Tacconi, 2011). Note that benefits and costs may be unequally distributed among individuals for the sake of net social gain.

Under rules-based theories, distributional outcomes are judged not on their own terms, but are considered just if they result from the application of fair rules. Human beings are valued as ends in themselves, never to be treated as the means to some other good (e.g. as ecosystem service providers). Thus, concern for the individual prevails over the aggregate: "justice denies that the loss of freedom for some is made right by a greater good shared by others" (Rawls, 1971:3-4). Table 1 highlights four different rules-based principles for judging the justice of distributional outcomes. Libertarian systems emphasise liberty in terms of equality of individual rights and opportunities for all members of society, regardless of the consequences for their relative attainment of wealth, well-being or any other kind of utility (Nozick, 1974). So long as they flow from the free exercise of equal rights (e.g. the honouring of property rights), extreme inequalities in outcome (e.g. property distribution) are to be tolerated. All distributional allocations arising from freely chosen transfers are considered fair (Konow, 2003).

Egalitarian systems demand equality in the distribution of benefits from a productive activity without regard for any pre-existing inequities. Shares of benefit/cost could be assessed in terms of quantitative measures, such as net income, or more integrative concepts, such as change in well-being (Konow, 2003; Sen, 1992). Merit-based distributions hold that rewards should be proportional to individual productive contributions or sacrifices made (i.e. opportunity costs) (Konow, 2003). A final major distributive notion - that just social allocations should reflect individual needs - is shared by a diverse set of theorists from John Rawls (1971) to Karl Marx. Both thinkers agree that justice (or injustice) is established by the basic structure of society, and distribution should therefore take account of the different needs arising from the inherent disadvantage suffered by some groups. 


\subsection{Procedural justice}

Procedural justice refers to fairness in the political processes that allocate resources and resolve disputes. It involves recognition, inclusion, representation and participation in decision-making (Fraser, 2009; Hillier, 1998; Schlosberg, 2007).

A chief critique of distributive theories of justice is that they ignore the causes and processes that construct injustice (Fraser, 2009; Schlosberg, 2007). This criticism has been levelled at PES schemes as market-based distributive mechanisms that only serve to exacerbate underlying inequities (e.g. McAfee and Shapiro, 2010). The question then arises whether promoting procedural justice by instituting inclusive, participatory processes to govern PES exchanges makes it possible to correct for unfair outcomes and/or to tackle causal origins.

\subsection{Contextual justice and capabilities}

To uncover the origins of injustice it is necessary to understand political processes and distributive outcomes in their social context. These sorts of considerations are often overlooked or underplayed in the design of development interventions. Moreover, to assess the social impact or fairness of a project or policy it is necessary to track not only the process and outcomes of implementation, but also to investigate initial social conditions - what kind of inequity is present at the starting point? These reasons make the case for the analytical and pragmatic utility of distinguishing a third dimension of justice, which is further developed in the discussion on equity below.

The basis for this distinction can be found in the literature in the communitarian critique of Rawls and distributive justice. Authors such as Pelletier (2010), Sandel (1990) and Walzer (1983) argue that justice is a situated phenomenon, i.e. that principles of justice must be understood within the context of the culture in question, with reference to beliefs, practices and institutions that guide actors.

Capability theory similarly questions liberal notions of justice founded on individuals with their autonomous preferences and rights. This influential approach (Nussbaum and Sen, 1993) links ethical, individually based conceptions of justice to the idea of 'social justice' operating at higher scales (community to global). 'Capabilities' are the capacities necessary for individuals to fully function in their chosen lives, the freedom and wherewithal to pursue the lives they value. For example: the capability of literacy is necessary for reading (Schlosberg, 2007). In order for citizens to exercise the vote, they first must have recognition as a member of the political community and a minimum level of education, information, security, and economic resources (e.g. transportation, ability to take time off work). Great asymmetries of wealth and power produce great asymmetries in capabilities and thereby 
distort democratic participation and subvert justice. The capabilities component of justice thus reveals the interdependence of distribution, procedure and recognition (Schlosberg, 2007). It also expands the scale of justice beyond the liberal focus on individuals to recognise that groups (e.g. communities of place, interest or ethnic identity) can also have capabilities, enjoy collective rights, suffer collective disadvantages, and form social movements.

\subsection{Participatory parity: an integrative principle}

For Fraser, the above dimensions of justice are united under the principle of "participatory parity", which posits that

justice requires social arrangements that permit all to participate as peers in social life. Overcoming injustice means dismantling institutionalised obstacles that prevent some people from participating on a par with others, as full partners in social interaction (2009:16).

It requires surmounting barriers to participation not only in the political sphere, but in all aspects of social engagement. Such an accomplishment would meet Sen's (2009) call for a global process of "public reasoning" towards locating an "overlapping consensus" (Rawls, 1971) on principles by which to guide public life. At any scale, where an initial shared grammar of justice is absent, participatory parity represents a process for generating contextually appropriate, functional definitions and standards.

Participatory parity is best understood as a goal to strive towards rather than an operational standard, since complete democracy exists nowhere. In particular, many REDD+ schemes will operate not within the (albeit flawed) systems of Western-style democracies, but rather in the context of non-representative systems of imposed decision-making. Analytically and aspirationally, however, participatory parity serves a crucial function in highlighting how the dimensions of justice are fundamentally interrelated. It underscores the fact that procedural justice cannot be achieved in a situation where people have vastly different capabilities to participate. For instance, a Free, Prior and Informed Consent regime will not effectively allow communities to defend and pursue their interests where they lack the information, time and experience to participate effectively (Szablowski, 2010).

\section{Equity framework}

The previous section reviewed the key elements in the justice literature that are significant for the assessment of equity: distribution, procedure, and context. Drawing on these ideas, we distil an analytical framework that can be used to examine, evaluate and plan for the impacts on equity of changes in value of ecosystem services in various contexts. The three 
dimensions of justice inform the core content of equity, or the first parameter of the framework, represented as the innermost layer in its diagrammatic depiction below (Figure 1). Together, these dimensions delimit and characterise the subject matter of equity as explicitly or implicitly defined in policies, projects and plans; in other words they answer the question: 'what counts as a matter of equity?' However, as discussed in Section 3.2, until the questions that frame the equity problem are also answered, any analysis or solution is incomplete. The framework therefore includes three additional, concentric parameters of meta-equity:

- 'who counts as a subject of equity?', which addresses the targets, or social scale of equity;

- 'why equity (or not)?', which considers the goals with regard to equity; and

- ' 'how are the parameters (what, who, why) of equity determined?' (cf. Fraser, 2009; Mahanty et al., 2006).

\section{Figure 1. Equity framework.}

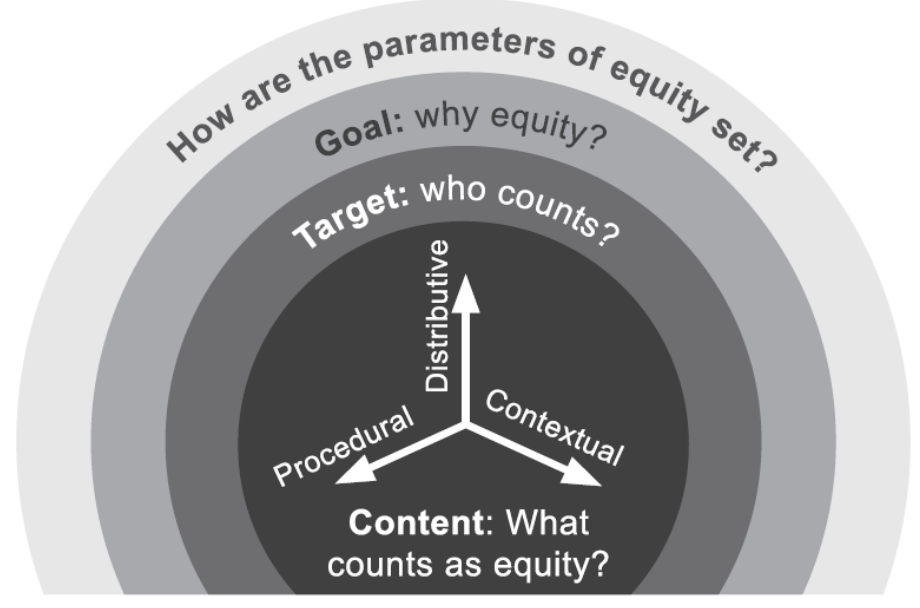

Note that the framework sets out guiding questions rather than specifying universally applicable standards. It allows for context-specific parameters to be generated, adopted and adaptively modified for a given intervention. Under ideal conditions these choices would be made through a process of participatory parity involving all affected parties. However, even an explicit process where the parameters are set by politicians, bureaucrats, or the analyst is superior to the more common practice of relying upon implicit, unarticulated and sometimes contradictory values and definitions.

\subsection{Content}

The content of equity constitutes the first parameter in the proposed framework. Applying our analysis of the justice literature, we distinguish three dimensions of equity. Note that most 
treatments of equity stop here, and many do not proceed past a one-dimensional focus on distribution.

\subsubsection{Distributive equity}

An evaluation of the social impact of an intervention that changes the value of ecosystem services must examine the distribution of costs, risks and benefits. This allocation can then be assessed in terms of one or more of the principles of distributive justice: equality, social welfare, merit and need (see Table 1 ). ${ }^{3}$ This sort of evaluation can reveal how communitybased forestry has evolved, for example, in Nepal. There some community forest user groups (CFUGs) began by targeting an equal distribution of costs (e.g. labour invested to guard the forest) and benefits (e.g. timber) for all members (Maharjan et al., 2009). Finding that the lack of appropriate equipment prevented poorer members from making use of their timber share, a utilitarian approach was instead employed to maximise net social welfare by selling the timber as a community and distributing the resulting profits (Maharjan et al., 2009). Merit-based systems are found in low-value Tanzanian community forestry, where the limited benefits are distributed primarily to members of the environmental management committee to reward their disproportionate input of effort (Vyamana, 2009). Current community forestry guidelines in Nepal are founded on a needs-based approach, with benefits specifically designed to improve the welfare of the least advantaged, most marginalised members of the community (Maharjan et al., 2009).

\subsubsection{Procedural equity}

In practice, standards for procedural equity can range from minimal guarantees of equal basic rights in decision-making and judicial processes to affirmative action favouring groups that have been marginalised with respect to natural resources, such as women, the landless and ethnic minorities.

Fraser (2009) and others (Schlosberg, 2007; Young, 1990) argue that the extent to which such groups are recognised within a socio-political system is a critical - often missing component in assessing procedural fairness. The equity framework thus underscores how meaningful public participation (participatory parity in the ideal) requires recognition of all parties and affirmative efforts to ensure their inclusion and representation. In the case of community forestry in Nepal, the key to achieving better distributive equity has been a focus by many donor projects on improving the procedural equity in CFUGs. This began with a

\footnotetext{
${ }^{3}$ Note that, for our purposes, there is no major distinction between distributive equity and distributive justice. However, although liberty (equal rights, equal opportunity) can be classed as a distributive principle of justice, we have categorised it under procedural equity in this framework in order to distinguish outcomes (distribution) from process (procedure).
} 
requirement that women and the most marginalised social group, the dalit caste, be recognised and included on CFUG committees and be given at least some of the key decision-making posts. Additionally, a strong focus on good governance (including wellbeing ranking to identify the poorest, empowerment classes for women, and public audits) gradually led to decision-making that responded more directly to the needs of marginalised groups (Schreckenberg and Luttrell, 2009).

\subsubsection{Contextual equity}

Brown and Corbera (2003:545) propose that, together with procedural and distributive equity, "equity in access" constitutes one of the three key elements of equity. We expand upon the notion of 'access' to encompass what we have termed 'contextual equity', which takes into account the uneven playing field (Larson and Ribot, 2007) created by the preexisting political, economic and social conditions under which people engage in and benefit from resource distributions - and which limit or enable their capacity to do both. Contextual equity removes the blindfold from legalistic Justice and acknowledges the initial distributions of access, capabilities and power from which people and nations engage in - or are swept up by - ecosystem services markets and agreements.

Ribot and Peluso (2003:153-154) define access as the "ability to derive benefit from things," which depends on a "web of powers" exercised through social relations and institutions such as markets, property, and informal, illicit and coercive claims to resources. In order to benefit from natural resources it is not only necessary to gain sanctioned or unsanctioned access to those resources themselves, but also to other critical resources: capital, labour, market networks, technology and information. Access operates not only at the level of individual capabilities and relationships, but at community and higher organisational levels.

Power enables actors to gain, control and maintain access to resources in two fundamental ways (Ribot and Peluso, 2003). Firstly, it enables some actors to affect, even direct, the practices and ideas of others (Lukes, 1986). Second, power is recreated through institutions and practices that can influence behaviour without any visible coercion (Foucault, 1979). Unequal power (re)produces inequity in its other dimensions. It underlies and compounds the inequitable distribution of resources and it strengthens certain voices in the political process while extinguishing others.

Looking through the integrative lens of contextual equity reveals how interventions in the value of ecosystem services are constrained by, and in turn transform, existing social institutions. For instance, some PES contracts have enabled local resource users and communities to formalise their customary claims to land. However, their relatively powerless 
position in this negotiation means that recognition may come at the price of restrictions on valued local land and forest uses, such as shifting cultivation (Mahanty et al., 2012). In ecosystem service markets, it is then possible to assess (i) how existing access and power relationships affect the ability of different social actors to win or lose from emerging ecosystem service markets; and (ii) whether this leads to greater or lesser social disparity. For instance, in Costa Rica's forest conservation PES scheme, payments were found to go disproportionately to farmers with higher levels of education, wealth and farm size (Muradian et al., 2010; Zbinden and Lee, 2005). Most assessments of equity limit their focus to the distribution of benefits, and sometimes, costs. Skipping over issues of procedural and contextual equity, such assessments are likely to miss many impacts that are harder to measure, but are often crucial to local welfare. Of particular concern is the potential of commodified ecosystem services to undermine traditional and other local institutions that (re)distribute resources, provide 'safety nets' for the poor, or establish sanctions for sustainable resource use (e.g. labour-sharing arrangements, patron-client relationships and belief-systems) (Birkenholtz, 2009; Kosoy and Corbera, 2010; Landell-Mills and Porras, 2002) .

\subsubsection{Linkages across dimensions of equity}

The development of Peru's law on access and benefit-sharing illustrates how distributive, procedural and contextual dimensions of inequity are inevitably interrelated (Ituarte-Lima and Subramanian, in press). In this case, mechanisms to overcome power imbalances in negotiations and help forest-dependent people comply with legal requirements included helping them gain formal legal status, providing widespread information about the law (in many formats and languages) and improving their ability to take advantage of the law by abolishing the fee to register collective knowledge of biodiversity (Ituarte-Lima and Subramanian, in press). These contextual and procedural changes were expected to improve distributive outcomes.

More generally, equity is violated where PES agreements are not fully voluntary compacts made between equal partners - equal with respect to resources and capabilities (distribution and context) as well as rights (procedure). This violation is in fact prevalent according to recent research on PES (Engel et al., 2008; Muradian et al., 2010). Thus, many advocates for forest and other resource-dependent peoples insist on Free, Prior and Informed Consent (FPIC) as a procedural equity criterion for all project activities (e.g. Colchester and Ferrari, 2007; Sikor et al., 2010). Yet, socio-political disparities can render such procedures all but meaningless. 
If those who control decision-making and access to resources tend to reap a disproportionate share of benefits (McDermott and Schreckenberg, 2009; Saito-Jensen et al., 2010), is the reverse also true? For instance, do improvements in procedural equity necessarily improve the distribution of benefits? Certainly distributive and procedural equity come together in the case of mining in Papua New Guinea, where benefit packages are negotiated through legally stipulated landowner forums (Filer, 2008). However, the causal link between fair outcomes and fair procedures is not always clear-cut. In the case of Bolivia, a laudable policy commitment to reduce inter-territorial disparities by redistributing tax revenue from gas-rich departments is being pursued through political decision-making processes in which central authorities decide, more or less unilaterally, to impose their vision of how hydrocarbon resources should be governed (Humphreys Bebbington, 2012). Poor procedural equity may thus underpin (and possibly undermine) an objective of achieving better distributional equity. Under conditions of massive social inequality, a fundamental choice may therefore be required between honouring tenets of procedural equity, such as following due process within a fundamentally inequitable society, and achieving an equitable distribution of resources.

Distributional, procedural and contextual equity should be seen as interdependent aspects of a multidimensional, multiscalar phenomenon whose interrelationships are currently poorly understood. In developing the framework, we are less concerned with precise distinctions between the dimensions than with ensuring that none of these elements of equity are overlooked by policymakers, planners and researchers. Distributional and procedural dimensions of a policy or project fall within the scope and control (at least initially) of its proponents. Yet, the capacity to achieve distributional and procedural equity is conditioned by context, which is not amenable to control. Its features (such as inequality and social marginalisation) may be transformable, but only with time, resources and focused effort. As a central case in point, one of the major, unresolved debates over REDD+ is the degree to which resources should be aimed at 'context'. In other words, to what degree should a policy aimed at sequestering the largest amount of carbon for the least cost be expected to alleviate poverty, reform land tenure and deliver other co-benefits?

\subsection{The framing of equity: targets, goals and parameter-setting}

\subsubsection{Target and scale}

Defining equity in terms of the above dimensions alone would leave open the crucial question: 'who counts as a subject of justice?', in other words, 'equity among whom?' (Fraser, 2009; Mahanty et al., 2006). According to Fraser (2009), this is a second-order, or meta-justice 'framing' issue that must first be specified in order to answer the first-order 
questions regarding the content (or dimensions) of justice. This set of questions could also be posed in terms of scale: 'at what social and temporal scale should equity be assessed?' Methodological and political consequences of considering equity at different temporal and social scales include:

- Individual. Assessing equity will involve comparing the differential capabilities, costs, benefits, risks and opportunities experienced by individuals within larger social units, factoring in variables like gender and age (Hart, 1992; Pagiola et al., 2010; Sen, 1990).

- Household. Here it is relevant to consider the extent to which households benefit or lose from distributions according to markers of social difference, such as class, caste, race, ethnicity, and occupation. These variables are known to influence the extent to which different households derive sustenance or surplus from natural resources and ecosystem services (Agrawal and Gibson, 2001; McDermott and Schreckenberg, 2009).

- Community. Inequities between localities - e.g. rural to urban, upstream to downstream, protected to degraded, and high to low commercial value - need to be considered at this scale. Locational conflicts of interest raise equity questions for policy makers, as when the daily livelihood demands of national park residents challenge international conservation values (Mahanty et al., 2006; Saito-Jensen et al., 2010).

- Along value chain. Ecosystem service value chains may be short and direct (e.g. upstream water producers to downstream users) or long and convoluted (e.g. tropical timber processed in China for sale as furniture in the UK). Institutional arrangements and differing levels of political and market power enable actors along value chains to benefit differentially from the process of value creation around a commodity (Ribot, 1998). Power relations in the natural gas value chain in Bolivia, for example, are highly asymmetrical, with strategic decision-making (and the associated high salaries) being concentrated in Santa Cruz, and even further afield in the international headquarters of the companies operating the gas fields (Humphreys Bebbington, 2012).

- (Inter)national-Global. The uneven distribution of natural resources and the historical effects of industrialisation, colonisation, extraction and trade have given rise to global inequities that give nations differential roles and power in relation to current ecosystem service markets. At the same time, as Northern nations are responsible for the vast majority of accumulated carbon emissions, the concentration of tropical forests in southern countries makes them targets for ecosystem service provision for mitigation, via REDD+ schemes. However, Northern interests are largely setting the terms of trade, in relation to the architecture of such schemes, and the contractual requirements and prices in specific deals (McAfee and Shapiro, 2010; Peskett et al., 2011a)

- Ecosystems. Some philosophers and activists argue that justice is not limited to human society, but must also embrace non-human species (Stone, 1972) and/or ecosystems as 
a whole (Jamieson, 2008; Schlosberg, 2007). Ecosystem service markets, however, prioritise only the human use value of ecosystem services.

- Intergenerational. Ecological economists (Howarth and Norgaard, 1990; Jamieson, 2008) argue that the interests of future generations are fundamental to 'sustainable development' (Brundtland, 1987). While ecosystem service agreements ostensibly aim to secure ecosystem services for future generations of ecosystem service 'buyers', they can also tie future generations of 'sellers' or service providers into long term constraints on resource use that span decades or longer (Peskett et al., 2011a).

The subject of equity, and by extension the scale at which equity is being considered, is thus an important starting point in assessing change in equity. Inter-scalar relationships feature significantly in initiatives, such as REDD+, that cut across all of these spatial and temporal scales. Inter-scalar trade-offs in equity may occur, for instance, if ecosystem service markets bring about global and national benefits yet cause or increase inequities at the local level.

\subsubsection{Goals}

Initiatives that change the value of ecosystem services directly or indirectly may have explicitly articulated equity goals or none at all. Failure to set goals with respect to equity leaves implicit equity goals unexamined, and precludes the consideration of equity standards or targets. This in turn thwarts the monitoring and evaluation of such impacts. Furthermore, it also disguises instances where trade-offs are required along multiple dimensions or scales of equity. Finally, it closes off the possibility for the 'subjects' of equity to participate in formulating the objectives of interventions affecting their lives.

Explicit equity goals might seek one of three generalised ends:

a) ignore equity;

b) do no harm, i.e. ensure no one is made worse off;

c) advance equity towards a net more equitable situation.

A purely market-based PES scheme could pursue ecosystem service provision (e.g. carbon sequestration, water harvesting) regardless of equity impact (Angelsen et al., 2009).

However, if the scheme aims to minimise or avoid causing harm, it may establish safeguards against worsening inequity. This is the case in certification schemes (McDermott, 2012) and most current negotiations on national REDD+ programmes (McDermott et al., 2012; Peskett et al., 2011a). Alternatively, if the goal is to improve social equity, the intervention would need to identify existing inequity, address its causes, and assess progress. Fairness in the allocation of benefits and risks from a project or policy could lead to an equity-neutral result, so a fairness criterion alone would not be adequate to this task. Just as the community 
forestry literature has shown that poverty reduction needs to be an explicit aim if it is to be achieved (Schreckenberg and Luttrell, 2009), so too the explicit articulation of equity goals of projects or policies is a precondition for equity to be addressed.

\subsubsection{Setting the parameters}

In different historical and cultural settings, the parameters of how societies define equity are under constant negotiation (Mahanty et al., 2006). Given the conflicting conceptions of equity prevailing, understanding how the goal, target and content of equity are established is a critical part of the design or evaluation of a project or policy. Different governance processes for setting equity parameters produce different substantive outcomes. This is illustrated, for example, by the two main global institutions for forest certification - the Forest Stewardship Council (FSC) and the Programme for Endorsement of Forest Certification (PEFC) (McDermott, 2012). By assigning equal votes to its environmental, social and economic 'chambers', the NGO-driven FSC prevents forest industry members from dominating decision-making. Rather, it emphasises the rights of indigenous peoples, local communities and workers, with strong representation particularly in the social chamber, to set the parameters of equity. In British Columbia, it was therefore possible for an FSC standard to be endorsed in complete absence of industry support. Although the private-sector driven PEFC also has a multi-stakeholder decision-making process, forest producers are the key parameter-setters, and thus the PEFC emphasises making certification more accessible to small-scale forest producers through the use of flexible standards with modest requirements (McDermott, 2012).

Designing a PES, REDD+, or indeed any policy, programme, or project intended to enhance equity (or avoid worsening inequity) similarly relies upon the prior establishment or assumption of the fundamental parameters of equity - who will define the values at stake, for whom, and how? Whether the parameters are set through democratic deliberation or dominant power structures, the equity framework can be applied as an analytical tool for teasing out underlying assumptions about how equity is defined and tracking how it is affected. Since there is no neutral or context-free way for arriving at a definition of equity, the framework requires an external means of setting parameters when called upon as a device for planning or critique. Participatory parity is proposed as an aspirational ideal for the parameter-setting process.

Short of that ideal, the equity framework can assist users in developing clear and explicit equity objectives and criteria - and in excavating those left implicit by others. Analysts and planners can then identify, conditionally resolve, and monitor the inevitable conflicts and trade-offs that arise among plural conceptions of equity, and between equity and other social 
goals. Ultimately, however, these are value-laden decisions that protagonists arrive at through a process of social contestation and political negotiation.

\section{Equity in relation to other guiding principles}

Equity is not the only consideration in designing and evaluating natural resource governance regimes and improvement schemes. Below we discuss how the proposed equity framework differs from and/or complements other key concepts and approaches.

\subsection{Rights and equity}

Human rights are a prominent focus in global debates over how to address climate change. Rights-based approaches affirm 'equal rights' for all, although their definition and derivation varies. Moser (2004:30) defines rights as, "legitimate claims that give rise to correlative obligations or duties" on the part of other persons or institutions "to assist the rights-holder in securing the right." Sen's (2009:358) notion of rights refers more generally to "ethical pronouncements" that demand recognition of the freedoms they identify and which others are obliged to promote or safeguard.

Rights are closely associated with justice, such that securing the former can be seen as a means of bringing about the latter. While rights language is undeniably persuasive, it can be imprecise with respect to critical issues. What set of fundamental rights is adequate to ensure justice? Who holds these rights, and who bears the duty to enforce them? Advocates have argued (e.g. Larson, 2011) that ensuring clear property rights will help guarantee that REDD+ will have a just or equitable outcome. Applying the equity framework analytic highlights the significance of the scale at which the rights are recognised (e.g. individual vs. community) and the importance of cross-scalar relationships (e.g. value chains). Moreover, defining equitable distributions on the basis of property rights raises difficulties in specifying not only the target, but the content of the right (e.g. forest, timber or carbon? non/commercial use? non/consumptive use?) (Sikor and Stahl, 2011). Finally, by what authority, or parameter-setting process, were the rights sanctioned (Sikor and Lund, 2009)? The fact that carbon rights are not yet legally defined in most of the world (Mahanty et al., 2012) brings this latter issue to the fore.

The likelihood of clashing 'rights' goes up as more rights (e.g. economic rights) are asserted, the universe of rights-holders (e.g. non-citizens) expands, and special classes of rightsholders (e.g. indigenous people) are designated. Critically, the assertion of rights does not in itself provide guidance for ordering or weighting rights that conflict with each other: my freedom vs. your well-being, growth vs. sustainability, privacy vs. speech, and indigenous rights vs. the rights of migrants (or majorities). 
Rather than accept as given a broad, putatively cross-cultural set of social and economic rights and assume that equity will follow, the proposed equity framework enables the user to identify or select an explicit set of parameters that define equity (goal, targets, content) in particular contexts, while at the same time pointing out the existence of opportunities to challenge inequity.

The meaning of rights as differently construed under different socio-cultural value systems is also a challenge in defining equity. The framework developed here sets out parameters by which to define and analyse equity, but does not attempt to universalise particular values. Systems with different internal valuations of equity can then be assessed and compared according to the framework's analytics and guiding questions. When planning a new project, programme or policy, participatory parity provides a normative basis for the process of defining equity, rather than issuing a judgment on the outcomes.

\subsection{Not by equity alone: effectiveness and efficiency}

Effective ecosystem service markets are often thought to require trade-offs between equity, effectiveness (delivery of ecosystem services) and efficiency (variously net social benefit or cost-effectiveness) (Angelsen, et al., 2009; Tacconi, 2011; Wunder, 2005). Although the relative weighting among the three goals is extrinsic to the framework, it can help analyse such trade-offs and clarify their consequences. For example, delivering land-based ecosystem services requires access to land, thereby excluding the landless from such PES schemes; delivering such services most efficiently favours participation by larger landowners, with predictable consequences for local equity (Grieg-Gran et al., 2005; Zbinden and Lee, 2005).

The equity framework helps to highlight that trade-offs also occur across temporal and geographic scales. For instance, an efficient PES carbon scheme could have locally inequitable results, yet have the potential to aid the global poor by averting the worst effects of climate change. The benefit to the most vulnerable of future generations would be incalculable. Consequently, adopting criteria such as 'do no harm' that are derived from an exclusively local construction of the equity problem could lead to the rejection of interventions that would combat inequity at wider scales.

Fundamental tensions can thus arise between equity at different scales, and between equity, efficiency and effectiveness. There is no framework that can be deployed to resolve these fundamental quandaries. What a framework can do is to guide analysis in order to make ethical and political dilemmas clear. Thus, equity must be understood as one in a portfolio of 
criteria. Since there are no universal ethical grounds for evaluating trade-offs between equity and other principles, we are thrown back upon participatory parity as the process for seeking an 'overlapping consensus' on the way forward.

\subsection{Equity and poverty}

The distinction between the goals of equity and poverty alleviation depends on how both are defined. For example, viewing poverty alleviation in terms of raising aggregate income or net social welfare (expanding the metaphorical social pie) could leave relative poverty untouched, or even worsen distributive equity. For instance, REDD+/PES interventions may benefit the moderately poor, e.g. by providing tree seedlings, but leave out the poorest, i.e. those without land to plant them on (Peskett et al., 2011b). The end result of such projects is to increase inequity even as poverty decreases overall. Conversely, a hypothetical project could make everyone worse off (the pie shrinks), but improve equity by reducing wealth disparities (more equally sized slices).

The more poverty is understood to be multidimensional, the closer and more complex the poverty-equity connection becomes, as a large theoretical and empirical body of literature attests (e.g. Nolan and Whelan, 2007; Sen, 1992; UNDP, 2011; World Bank, 2000). In fact, each can be understood to be a dimension of the other, such that we find that an equityfocused analysis can shed new light on efforts both to alleviate poverty and to protect the interests of the poor and marginalised in pursuit of other goals. Equity provides a way of characterising the distribution of power and resources at a given place and time: interventions to alleviate poverty must attempt to re-order these relationships in order to have more than a very local effect. If we then draw parallels between ecosystem services as relatively new, abstract land-based commodities and long-standing resource-based commodity markets (e.g. timber, oil), evidence from the latter (Ross, 1999) suggests the need to question very carefully the assumption that ecosystem service markets will prove to be wealth-generators for the poor and equity-enhancers for society as a whole.

If PES schemes are to have any prospect of redressing poverty, they must tackle its drivers and confront inequity at an effective scale. More commonly, PES proponents instead emphasise environmental outcomes, either neglecting to mention poverty reduction altogether, or tacking it on as a potential co-benefit (Wunder, 2008). Critics argue to the contrary that PES, as a market-based strategy operating in a world with massively unequal distribution of ownership and buying power, is bound to reinforce deep-rooted structural causes of poverty and thereby exacerbate inequity as well as poverty-induced environmental degradation and vulnerability (Corbera and Brown, 2010; McAfee and Shapiro, 2010). This theoretical debate can only be resolved empirically. The framework proposed here can 
support such an investigation by revealing the multiple dimensions along which to analyse and evaluate equity conditions, processes and outcomes.

\section{Conclusion}

We argue that a fully specified definition of equity is indispensible to just and effective policy, planning, and assessment of the social impacts of change in the value of ecosystem services. In contrast, much of the current policy discourse on climate change seems to relegate equity to distribution alone. We contend that the three interdependent dimensions of equity - distribution, procedure, and the contextual disposition of capabilities, access and power - all contribute to the degree of (in)equity in the social condition. Thus, interventions designed solely to distribute payments for ecosystem services, without attention to local decision-making inputs, access to resources, and power relations, are unlikely to have equitable consequences. Further research is needed to understand the dynamic interactions between these dimensions and how they are affected by changes in values of ecosystem services.

In addition to illustrating the multiple, interlinked dimensions of equity, this framework highlights the importance of often overlooked framing parameters. First, it matters whether the goal of an initiative is to maximise gains in social equity, or merely to 'safeguard' it. Second, the specification of socio-spatial and temporal scale defining who is targeted makes a profound difference. Framed too expansively, local suffering and exclusion go unattended; yet, an excessively narrow frame will miss the causes of inequity, neglect affected non-local parties, and exclude potential long-term solutions to social and environmental problems. While the framework itself does not incorporate nearly all the factors affecting the impacts on equity of payments for ecosystem services, it does identify the essential elements of equity that must be evaluated in order to conduct such an assessment. Of these, perhaps the most frequently overlooked is the final framing parameter: the process of defining equity in a given context. Without explicit attention, such a process is likely to remain subterranean, reflect dominant discourses, and reproduce prevailing power relations that constrain the possibilities for the progressive transformation of inequity. In this respect the full implications of the equity framework are not value-neutral. For analysts as well as polities, the systematic analysis of equity enables open and inclusive parameter-setting processes that involve debating the fundamental ethical values at stake in defining equity, with affirmative efforts to represent and amplify marginalised voices. Participatory parity suggests a way to muddle through the process of negotiating contending values and interests towards a shared, or working, conception of equity as a social goal. 


\section{Acknowledgements}

This research is an output of the project, 'Safeguarding local equity as global values of ecosystem services rise' (NE/I00341X/1), funded with support from the Ecosystem Services for Poverty Alleviation Programme (ESPA). The ESPA programme is funded by the Department for International Development (DFID), the Economic and Social Research Council (ESRC) and the Natural Environment Research Council (NERC). The funder had no involvement in study design or writing of the report. The authors thank our project team members (Denise Humphreys Bebbington, Trevor Birkenholtz, Emily Brickell, Lauren Coad, Kristy Graham, Pam Gregory, Claudia Ituarte-Lima, Richard Kimbowa, Mario Piedra Marin, Connie McDermott, Bernhard Mohns, David Mwayafu, Leo Peskett, Jesse Ribot and Ben Vickers) and other participants (Tom Clements, Janet Fisher, Amarinder Kaur, Hing Mesa, Dawn Robinson, Thomas Sikor, and Helen Suich) at two project workshops for their helpful comments during the development of this framework, as well as two anonymous reviewers for their insights and constructive criticism.

\section{References}

Agrawal, A., Gibson, C.C. (Eds.), 2001. Community-based Conservation. Rutgers University Press, New Brunswick, NJ.

Angelsen, A., with Brockhaus, M., Kanninen, M., Sills, E., Sunderlin, W. D. and WertzKanounnikoff, S. (Eds). 2009. Realising REDD+ National strategy and policy options. CIFOR, Bogor, Indonesia.

Birkenholtz, T., 2009. Irrigated landscapes, produced scarcity, and adaptive social institutions in Rajasthan, India. Annals of the Association of American Geographers 99 (1), 118-137.

Brown, K., Corbera, E., 2003. Exploring equity and sustainable development in the new carbon economy. Climate Policy 3, S41-S56.

Brundtland, G. (ed.), 1987. Our common future: The World Commission on Environment and Development. Oxford University Press, Oxford.

Colchester, M, Ferrari, M.F., 2007. Making FPIC work: challenges and prospects for indigenous people. Forest Peoples Programme, Moreton-in-Marsh. Available at: http://www.forestpeoples.org/sites/fpp/files/publication/2010/08/fpicsynthesisjun07eng .pdf [Accessed 18 Sept 2012]

Corbera, E., Brown. K., 2010. Offsetting benefits? Analyzing access to forest carbon. Environment and Planning A, 42, 1739-1761.

Corbera, E., Schroeder, H., 2011. Governing and implementing REDD+. Environmental Science and Policy 14(2), 89-99.

Diaz, D., Hamilton, K., Johnson, E., 2011. State of the Forest Carbon Markets 2011: From 
Canopy to Currency. Forest Trends and Ecosystem Marketplace, Washington DC.

Engel, S., Pagiola, S., Wunder, S., 2008. Designing payments for environmental services in theory and practice: An overview of the issues. Ecological Economics 65, 663-674.

Filer, C. 2008. Development Forum in Papua New Guinea: Upsides and Downsides. Journal of Energy and Natural Resources Law, 120-150.

Fisher, R.J., 1989. Indigenous systems of common property forest management in Nepal.

Working Paper No. 18. Environmental and Policy Institute of East West Center, Hawaii.

Foucault, M., 1979. Discipline and Punish. New York, Vintage.

Fraser, N., 2009. Scales of justice; reimagining political space in a globalising world. Columbia University Press, New York.

Ghazoul, J., Butler, R.A., Mateo-Vega, J., Pin Koh, L., 2010. REDD: a reckoning of environment and development implications. Trends in Ecology and Evolution 25(7), 396-402.

Grasso, M., 2007. A normative ethical framework in climate change. Climatic Change 81, 223-246.

Grieg-Gran, M., Porras, I., Wunder, S., 2005. How can market mechanisms for forest environmental services help the poor? Preliminary lessons from Latin America. World Development 33(9), 1511-1527.

Hart, G., 1992. Imagined unities: Constructions of "the household" in economic theory, in: Ortiz, S., Lees, S. (Eds.), Understanding Economic Process. University Press of America, N.Y., pp 111-130.

Heyward, M., 2007. Equity and international climate change negotiations: a matter of perspective. Climate Policy 7, 518-534.

Hillier, J., 1998. Beyond confused noise; ideas toward communicative procedural justice. Journal of Planning Education and Research 18, 14-24.

Howarth, R., Noorgard, R., 1990. Inter-generational rights, efficiency and social optimality. Land Economics 66, 1-11.

Humphreys Bebbington, D., 2012. Extraction, inequality and indigenous peoples: Insights from Bolivia. Environmental Science and Policy, http://dx.doi.org/10.1016/ j.envsci.2012.07.027, in press.

Ituarte-Lima, C., Subramanian, S., (in press), Retreading negotiations on equity in environmental governance: Case studies contrasting the evolution of ABS and REDD plus, in: Maes, F. (Ed.), Linking Climate Change and Biological Diversity, Edward Elgar Publishing, Cheltenham, UK and Northampton, MA, USA.

Jamieson, D., 2008. Ethics and the Environment. Cambridge University Press, Cambridge. Klinsky, S., Dowlatabadi, H., 2009. Conceptualizations of justice in climate policy, Climate Policy 9(1), 88-108. 
Konow, J., 2003. Which is the fairest one of all? A positive analysis of justice theories. Journal of Economic Literature XLI, 1188-1239.

Kosoy, N., Corbera, E., 2010. Payments for ecosystem services as commodity fetishism. Ecological Economics 69, 1228-1236.

Landell-Mills, N., Porras, T.I., 2002. "Silver bullet or fools' gold? A global review of markets for forest environmental services and their impact on the poor". Instruments for sustainable private sector forestry series. IIED, London.

Larson, A.M., 2011. Forest tenure reform in the age of climate change: Lessons for REDD+. Global Environmental Change 21 (2), 540-549.

Larson, A.M., Ribot, J.C., 2007. The poverty of forestry policy: double standards on an uneven playing field. Sustainability Science 2(2), 189-204.

Lukes, S., 1986. Power. NY University Press, New York.

MA, 2005. Our Human Planet: Summary for Decision Makers. Millennium Ecosystem Assessment. World Resources Institute, Washington, DC.

Mahanty, S., Milne, S., Dressler, W., Filer, C., 2012. The Social Life of Forest Carbon: property and politics in the production of a new commodity. Human Ecology 40 (5), 661-664.

Mahanty, S., Fox, J., Nurse, M., Stephen, P., McLees, L., 2006. Hanging in the Balance: Equity in Community-Based Natural Resource Management in Asia. 'Eleventh Workshop on Community Management of Forest Lands: Equity in CBNRM', RECOFT, Bangkok and East-West Center, Hawaii.

Maharjan, M.R., Dhakal, T.R., Thapa, S.K., Schreckenberg, K., Luttrell, C., 2009. Assessing the benefits of pro-poor community forestry in the Nepal Churia region. International Forestry Review 11(2), 254-267.

McAfee, K., Shapiro, E., 2010. Payments for ecosystem services in Mexico: Nature, neoliberalism, social movements, and the state. Annals of the Association of American Geographers 100(3), 579-599.

McDermott, C., 2012. Applying an "equity framework" to compare certification schemes across product sectors and scales. Environmental Science and Policy, http://dx.doi.org/ 10.1016/j.envsci.2012.06.008, in press.

McDermott, C., Coad, L., Helfgott, A., Schroeder, H., 2012. Operationalizing social safeguards in REDD+: actors, interests and ideas. Environmental Science and Policy, $21,63-72$.

McDermott, M.H., Schreckenberg, K., 2009. Equity in community forestry: Insights from North and South. International Forestry Review 11(2), 157-170.

Moser, C., 2004. Rights, power and poverty reduction in: Alsop, R., (ed.), Power, Rights and Poverty: Concepts and Connections, The World Bank, Washington D.C. and DFID, London, pp. 29-50. 
Muradian, R., Corbera, E., Pascual, U., Kosoy, N., May, P., 2010. Reconciling theory and practice: An alternative conceptual framework for understanding payments for environmental services. Ecological Economics 69, 1202-1208.

Nolan, B., Whelan, C., 2007. On the multidimensionality of poverty and social exclusion. In: Jenkins, S., Micklewright, J. (Eds.), Inequality and Poverty Re-examined. Oxford University Press, Oxford.

Nozick, R., 1974. Anarchy, State, and Utopia. Basic Books, New York.

Nussbaum, M.C., Sen, A. (Eds.), 1993. The Quality of Life. Clarendon Press, Oxford.

O.E.D. 2010. Oxford English Dictionary. Online at: http://oxforddictionaries.com [Accessed 18 Sept 2012]

Ostrom, E., 2009. A general framework for analyzing sustainability of social-ecological systems. Science 325, 419-22.

Pagiola, S., Rios, A.R., Arcenas, A., 2010. Poor household participation in Payments for Environmental Services: Lessons from the silvopastoral project in Quindio, Colombia. Environmental \& Resource Economics 47(3), 371-394.

Pascual, U., Muradian, R., Rodriguez, L., Duraiappah, A., 2010. Exploring the links between equity and efficiency in payments for environmental services: A conceptual approach. Ecological Economics 69, 1237-1244.

Peskett, L., Huberman, D., Bowen-Jones, E., Edwards, G., Brown, J., 2008. Making REDD work for the poor. A Poverty Environment Partnership Report. Overseas Development Institute, London. Available at: http://www.odi.org.uk/resources/docs/3451.pdf [Accessed 18 Sept 2012]

Peskett, L., Vickers, B., Graham, K., 2011a. Equity issues in REDD+. Working paper. Available at: http://redd-net.org/resource-library/equity-issues-in-redd+ [Accessed 18 Sept 2012]

Peskett, L., Schreckenberg, K., Brown, J., 2011b. Institutional approaches for carbon financing in the forest sector: Learning lessons for REDD+ from forest carbon projects in Uganda. Environmental Science and Policy 14, 216-229.

Pelletier, N., 2010. Environmental sustainability as the first principle of distributive justice: Towards an ecological communitarian normative foundation for ecological economics. Ecological Economics 69, 1887-1894.

Rawls, J., 1971. A Theory of Justice. Harvard University Press, Cambridge, MA.

Rawls, J. (ed.), 2001. Justice as fairness: a restatement. Harvard University Press, Cambridge, MA.

Resnick, J., Curtis, D., 2010. Representing Justice: Invention, Controversy, and Rights in City-States and Democratic Courtrooms. Yale University Press, New Haven and London.

Ribot, J., 1998. Theorizing access: forest profits along Senegal's charcoal commodity chain. 
Development and Change 29, 307-341.

Ribot, J., Peluso, N., 2003. A theory of access. Rural Sociology 68, 153-181.

Ross, M.L., 1999. The political economy of the resource curse. World Politics 51, 297-322.

Saito-Jensen, M., Nathan, I., Treue, T., 2010. Beyond elite capture? Community-based natural resource management and power in Mahmmed Nagar village, Andhra Pradesh, India. Environmental Conservation 37, 327-335.

Samuelson, P., 1947, Enlarged ed. 1983. Foundations of Economic Analysis, Harvard University Press, Cambridge, MA.

Sandel, M., 1990 Liberalism and the limits of justice. Cambridge University Press, Cambridge.

Schlosberg, D., 2007. Defining Environmental Justice: Theories, Movements and Nature. Oxford University Press, Oxford.

Schreckenberg, K., Luttrell, C., 2009. Participatory forest management: a route to poverty reduction? International Forestry Review 11(2), 221-238.

Schroeder, D., Pisupati, B., 2010. Ethics, Justice and the Convention on Biological Diversity. United Nations Environment Program and University of Central Lancashire, UK.

Sen, A., 1990. Gender and cooperative conflicts in: Tinker, I. (ed.), Persistent Inequalities. Oxford University Press, Oxford, pp. 123-149.

Sen, A., 1992. Inequality Re-examined. Oxford University Press, Oxford.

Sen, A., 2009. The Idea of Justice. Belknap Press, Cambridge, MA.

Sikor, T., Lund, C., 2009. Access and property: A question of power and authority. Development and Change 40 (1), 1-22.

Sikor, T., Stahl, J., Enters, T., Ribot, J., Singh, N., Sunderlin, W., Wollenberg, L,. 2010. REDD-plus, forest people's rights and nested climate governance. Global Environmental Change 20(3), 423-425.

Stone, C., 1972. Should trees have standing? Towards legal rights for natural objects. Southern California Law Review 45, 450-501.

Szablowski, D., 2010. Operationalizing Free, Prior, and Informed Consent in the extractive industry sector? Examining the challenges of a negotiated model of justice. Canadian Journal of Development Studies 30(1-2), 111-130.

Tacconi, L., 2011. Redefining payments for environmental services. Ecological Economics, 73 (15): 29-36.

Tisdell, J., 2003. Equity and Social Justice in Water Doctrines. Social Justice Research, 16(4), 401-415.

TEEB, 2010. The Economics of Ecosystems and Biodiversity: Mainstreaming the economics of nature: A synthesis of the approach, conclusions and recommendations of TEEB [online] available at: http://www.teebweb.org [Accessed 18 Sept 2012].

UNDP, 2011. Human Development Report 2011. Sustainability and equity: a better future for 
all. Palgrave MacMillan, New York.

Vyamana, V.G., 2009. Participatory forest management in the Eastern Arc Mountains of Tanzania: who benefits? International Forestry Review 11/2), 239-253.

Walzer, M., 1983. Spheres of Justice: A Defense of Pluralism and Equality. Basic Books, Inc., New York.

World Bank, 2000. World Development Report 2000/2001: Attacking poverty. World Bank, Washington, DC. and Oxford University Press, Oxford.

Worthington, S., 2006. Equity. Oxford University Press, Oxford.

Wunder, S., 2005. Payments for Environmental Services: Some Nuts and Bolts. Occasional Paper No. 42, CIFOR, Bogor, Indonesia.

Wunder, S., 2008. Payments for environmental services and the poor: concepts and preliminary evidence. Environment and Development Economics 13, 279 -297.

Young, I., 1990. Justice and the Politics of Difference. Princeton University Press, Princeton, NJ.

Zbinden, S., Lee, D.R., 2005. Paying for Environmental Services: An Analysis of Participation in Costa Rica's PSA Program. World Development 33(2), 255-272. 